\title{
Research on BIM 5D in the Cultivation of Civil Engineering Professionals in Applied Undergraduate Colleges
}

\author{
Jing Li $\mathbf{i}^{*}$ \\ East University of Heilongjiang, Harbin 150066, Heilongjiang Province, China \\ *Corresponding author: Jing Li, 22323612@qq.com
}

\begin{abstract}
Informatization is one of the main characteristics of the modern construction industry. As an important part of the construction industry, the application of BIM 5D has greatly promoted the transformation of the production mode in the construction field. The development of the construction industry is inseparable from the training of professional talents by universities. More and more universities are actively exploring the role of BIM 5D in the process of talent training. Based on the research on BIM 5D in the training of civil engineering professionals in applied undergraduate colleges in combination with examples, this research proposes that the teaching reform path should be guided by BIM 5D training courses to drive a series of main courses teaching reforms. With BIM as the characteristic of running a school, it provides ideas for the training of civil engineering professionals.
\end{abstract}

Keywords: BIM 5D; Civil engineering; Talent training; Integration of production and education; Education reform

Publication date: November 2021; Online publication: November 30, 2021

\section{Introduction}

Upon entering the 21st century, the rapid rise of the Chinese economy has led to the rapid development of the construction industry along with more complex construction technology. The traditional computer aided design (CAD) drawing method is not able to reflect the basic structures of buildings and project costs. Therefore, the building information modeling (BIM) technology came into being. After performing a threedimensional modeling of the proposed project, BIM would perform basic check calculations on the model according to the specific requirements of the building, and finally use Project Implementation Plan (PIP) and other technologies to comprehensively consider the project schedule and budget, optimize the entire construction cycle on the basis of 5D, as well as realize the real-time and accurate control of the system ${ }^{[1]}$. Some civil engineering colleges and universities in China have integrated BIM simulation technology in both undergraduate and graduate education as well as formed various forms of BIM 5D professional talent education and training models, including course teaching, school professional associations, research center training, etc. ${ }^{[2]}$. The application of BIM has become a core competency that civil engineering professionals must master to provide services to the society. Enhancing the employment competitiveness of students and cultivating technical professionals who are familiar with the technology are urgent issues to be solved in the cultivation of the core competence of civil engineering majors in applied undergraduate colleges.

\section{Research and development of BIM at home and abroad}

In 1975, Professor Chunk Eastman from Georgia Institute of Technology pointed out a computer-based description of a building in his topic, Building Description System, which was the earliest BIM concept at 
that time, promoting the visualization and quantitative analysis of the development of engineering projects ${ }^{[3]}$. The basic idea is to provide a more powerful software based on 3D geometric models, including building information and other information that supports open standards in order to improve the efficiency and level of planning, design, construction management, operation, and maintenance of construction projects. Japan has also promoted the integration of BIM in an all-rounded way. The research on BIM in various countries has gradually deepened, and great improvements have been made in the fields of dynamic collaborative decision-making and 5D scheduling, integrated delivery design, as well as Revit technology.

Comparatively, China's research on BIM started late, and its application in construction is still in its infancy. It is mostly used in small projects, and its functions cannot be fully utilized. In 2008, the China Academy of Building Research and other units jointly drafted the Industrial Base Platform Specification (GB/T25507-2010), which transformed Industry Foundation Classes (IFC) (ISO/PAS 16739:2005) into a national standard ${ }^{[4]}$. In 2009, the National Housing Engineering Center conducted a research on the BIM standard and proposed the China BIM Standard (CBIMS), which mainly includes three parts: data format standard, information classification, as well as data dictionary and process rules.

\section{Teaching research of BIM 5D in domestic and foreign universities}

According to statistics, $70 \%$ of colleges and universities in the United States have integrated BIM into their curriculum teaching. For example, the Pennsylvania State University and California Institute of Technology. In addition to that, eight colleges and universities in Singapore are offering 30 full-time BIM courses and 14 on-the-job BIM courses ${ }^{[5]}$. In addition, many universities in Taiwan and Hong Kong are also offering BIM courses.

In China, more and more design institutes, construction units, and development companies are aware of the impact of BIM on the entire industry and have begun to introduce BIM. The demand for BIM talents is huge. As of 2015, more than 2,500 full-time students and 8,500 in-service professionals have completed BIM-related training. Two-thirds of civil engineering colleges have BIM modules in their courses. According to a survey, many well-known local institutions of higher learning such as Tsinghua University, Harbin Institute of Technology, Huazhong University of Science and Technology, Tianjin University, Guangdong Ocean University, Shenyang Jianzhu University, etc. have started to offer BIM courses ${ }^{[5]}$.

Although the training of BIM 5D talents is on the right track, in reality, there are still problems and room for reform in its teaching. The problems of BIM 5D in teaching would be discussed below.

\subsection{Lack of curriculum support resources}

BIM 5D takes the BIM integration platform as the core, integrates professional models, such as civil engineering, steel structure, and electromechanics, uses the integrated model as the carrier to integrate the progress, contracts, costs, quality, safety, materials, labor, and other information in the construction process into the same platform, as well as provides information, quantity, resources, etc. for schedule management, contract cost management, material management, etc. within the planned period of the construction process, so as to achieve effective project decision-making and refined management. At present, the course teaching of BIM 5D includes the professional model, schedule, engineering quantity list and price information, threedimensional site layout information, contract information, as well as quality and safety information, which have been built into the software package. In the teaching process, information can be imported according to the teaching needs. Although it is fast, it is highly dependent on the software package. Other related professional courses have no connection with BIM 5D courses. Its teaching is not a system, and its teaching effect needs to be further improved ${ }^{[6]}$. 


\subsection{A shallow degree of integration of production with education}

In the process of talent training, colleges and universities should not only pay attention to theoretical teaching, but also to use actual projects as the carrier, carry out case practice teaching, and implement BIM integrated management throughout the life cycle of the project. There is a lack of school-enterprise cooperation and insufficient integration of production, education, and research. In addition, the lack of systematic supporting textbooks, improper curriculum settings, and insufficient teachers in the teaching process of such courses in colleges and universities are also important factors that influence the teaching effect of BIM courses ${ }^{[6]}$.

\section{The reform and innovation of BIM $5 \mathrm{D}$ in civil engineering}

\subsection{Regulations on BIM 5D for talent training}

Taking civil engineering as an example, when formulating a new talent training plan, skills training can be considered as the center to form a specific description predicated on competency-based education (CBE), such as using a BIM related software to establish a BIM model, and then using the BIM model to form a five-dimensional application (the five-dimensional model, which adds cost and schedule on the basis of the three-dimensional model), which integrates project cost information, project schedule information, and engineering quantity information, simulates the 5D model of building components and construction schedule during the entire construction process, as well as dynamically simulates construction changes to achieve the purpose of schedule control, investment control, quality control, contract management, and resource management.

\subsection{Setting a curriculum system that aims at cultivating BIM application skills}

The visual characteristics of BIM can be used to improve the efficiency of traditional teaching. For example, when teaching architectural drawing, teachers would teach by organizing construction site visits or by using pictures, videos, PowerPoint (PPT) slides, or other resources in classrooms. Some students are unable to understand and master due to poor foundation and the lack of spatial imagination. During on-site visits, there are hidden dangers, raising personal safety issues for both teachers and students. BIM technology training, virtual simulation teaching, and AR or VR (augmented reality or virtual reality) application can simulate the whole process of construction by establishing a building model. In addition, through the combination of professional core curriculum theoretical knowledge learning and BIM skills training, students can comprehensively cultivate their BIM application skills, such as BIM site layout, BIM professional modeling training, BIM 5D project management training, etc.

\subsection{Selection of BIM 5D technical teaching materials}

BIM training requires students not only to understand the theoretical knowledge of the course, but also to master BIM 5D related technologies. This requires the use of BIM 5D in teaching based on the original theory; that is, by allowing students to learn through practical training courses in order to make learning easier for students. Therefore, it is necessary to have the support of comprehensive practical training course materials in order to achieve the purpose of teaching. Generally speaking, the setting of course objectives usually includes textbooks, syllabus, PPT, teaching videos, tests, etc. The existing reference materials include Revit construction training, Revit electromechanical training, MagiCAD electromechanical training, office building BIM 5D architectural engineering drawings, architectural drawing recognition and BIM 5D modeling trainings, BIM 5D bidding training (sand table), BIM 5D construction engineering measurement and pricing trainings, etc. 


\subsection{BIM 5D construction training room}

The BIM 5D construction training room takes BIM 5D technology as the core and realizes project-oriented training at all stages: design, bidding, cost, and construction. It takes complete actual projects as the main body. It is task-driven and uses BIM 5D technology as well as simulation technology to realize virtual construction. The BIM 5D integration course in engineering is a training that includes the whole process from design to completion. Based on BIM 5D technology, through the simulation of the entire construction phase application (project design - bidding stage - project preparation stage - project implementation stage - completion stage), students would be able to master the actual business of future work sites. The management and application of BIM 5D technology would strengthen the cultivation of students' BIM 5D application skills and actual business skills. In order to achieve the learning goals, the construction training room should include an engineering bidding training room, a project management training room, as well as an engineering measurement and pricing training room.

\subsection{Promote the teaching reform of a series of main courses while taking the BIM 5D training course as a guide}

For a long time, teachers of various professional courses have been choosing teaching cases according to the specific course content, and these teaching cases are often independent of each other. The BIM knowledge system involves many professional courses, and its professional knowledge from design, construction, cost, to project management is interrelated and progressive. If each course chooses different cases, the teachers would teach based on their own textbooks and cases, which would not reflect the graduality and continuity of BIM case teaching. This is not conducive for the reflection of the BIM concept; in addition, the students' BIM knowledge would be scattered and disorganized. BIM 5D training is based on the model with the BIM platform as the core, and through model integration as well as information import, the project management application of the entire project is realized. In addition to the models and data provided by the BIM 5D software package, in the entire teaching process of the talent training program, certain engineering examples can be combined to actively promote teaching reforms in the main courses and accumulate data information for BIM 5D training courses.

In terms of curriculum evaluation, a curriculum reform model of project-oriented and visualized evaluation process should be constructed. BIM 5D training is project-oriented and task-driven, giving full play to the visual advantages of the technology. Teaching and learning as well as teaching and practice are presented in a three-dimensional visualization environment. In the teaching process, the BIM 5D threedimensional model library, micro-course teaching videos, online course resources, etc. should be utilized to the fullest to achieve a variety of mixed teaching methods as well as improve the teaching effect and the quality of talent training. Therefore, course evaluation should be based on process evaluation, supplemented by the results at the end of the term.

\subsection{Teaching methods and application of BIM 5D}

First, BIM 5D requires professional models, schedules, cost documents, etc. Students may not have the foundation or time to complete them. At this time, the instructor should provide relevant documents, such as the BIM 5D architectural engineering drawing of office buildings, BIM 5D installation engineering drawing of office buildings, etc., to ensure the smooth progress of the course.

The second is BIM 5D team building. The completion of a project should be completed not only by one major, but by multiple majors. It also needs to be completed according to different work stages. Therefore, the construction of the BIM 5D work team is a basic task that should be completed. In the learning process, the construction of professional work teams can be simulated. For example, the team 
composition can be as follows: (1) teacher team - five teachers with professional qualification certificate (the team leader as the BIM manager, a civil engineering teacher, an engineering cost professional teacher, an urban planning teacher, and an engineering management teacher); (2) student team - 40 students (urban planning major: 5 students; civil engineering: 5 students; engineering cost major: 5 students; project management: 255 students); (3) technical team - five to eight people (four senior BIM engineers and 2 professional senior engineers and professors). The student team management can formulate a series of management systems according to the institution's situation, such as student group management, enterprise evaluation, credit exchange system, scholarship payment system, etc. ${ }^{[5]}$.

In addition, students can also be encouraged to participate in various types and levels of BIM competitions. Interest is the best teacher for students. Use all possible opportunities to encourage students to participate in the offline China Price Association, the online and offline BIM 5D modeling contest, the architectural drawing held by the China Education Association, the BIM5D installation contest, the China BIM 5D application skills contest, and other professional competitions, in order to improve students' learning interest and application skills ${ }^{[5]}$.

\section{Conclusion}

BIM 5D is an integrated platform with a high degree of coordination, simulation, and visibility, which can greatly improve the application of original knowledge and technology as well as create higher economic benefits through the application of data, simulation, and other technologies. At present, with the widespread application of BIM-related technologies, talents who master and flexibly use BIM 5D are far from being able to meet the market demand. Therefore, the informatization teaching reform based on BIM 5D would become a new mode of teaching reform, and BIM 5D professional courses would become mandatory courses in order to cultivate project integration management talents. Project integration management based on BIM 5D is a necessary skill for students to work and engage in information management throughout the life cycle of a project after mastering the relevant BIM 5D basic software. Based on engineering examples, task-driven teaching reforms should be carried out in the production process. Driven by BIM 5D training courses, a series of main courses teaching reforms should be implemented and integrated training should be established. In this manner, the teaching effect and the quality of talent training can be improved. Therefore, applying BIM 5D to the cultivation of the core competitiveness of civil engineering majors is the only way for the future development of these majors in colleges and universities.

\section{Funding}

This research was supported by the Research of the Curriculum System for Civil Engineering Major of Applied Undergraduate Colleges Based on BIM5D (Project Number: HDFHX170318).

\section{Disclosure statement}

The author declares that there is no conflict of interest.

\section{References}

[1] Sun C, Jiang F, Man Q, 2014, Comment on the Application Ability of BIM Technology in the Construction Industry. Journal of Engineering Management, 28(3): 27-31.

[2] Bai S, Kou Q, Li W, et al., 2015, Practice and Thinking on BIM Talent Training in Civil Engineering Colleges and Universities. Civil Engineering Information Technology, 7(4): 99-102. 
[3] Eastman C, Fisher D, et al., 1974, An Outline of the Building Description System. Institute of Physical Planning, Carnegie-Mellon University, Pittsburgh.

[4] Cai R, Chen Q, Jia J, 2015, The Research Progress of BIM Technology and the Application of Related Software. Shanxi Architecture, 41(18): 234-235.

[5] Xu W, 2019, The Ability Training and Research of BIM Technology of Applied Undergraduate Engineering Management Under the Guidance of CBE Concept. Research on Communication Power, 3(02): 190-191.

[6] Jin Y, 2019, Research on the Teaching Reform of BIM5D Training Courses Based on Engineering Examples. Educational Modernization, 6(79): 58-59. 